Supporting Information

\title{
Synthesis and magnetic investigation of ordered mesoporous 2-line ferrihydrite
}

Harun Tüysüz, Elena Lorena Salabaş, Claudia Weidenthaler, Ferdi Schüth*

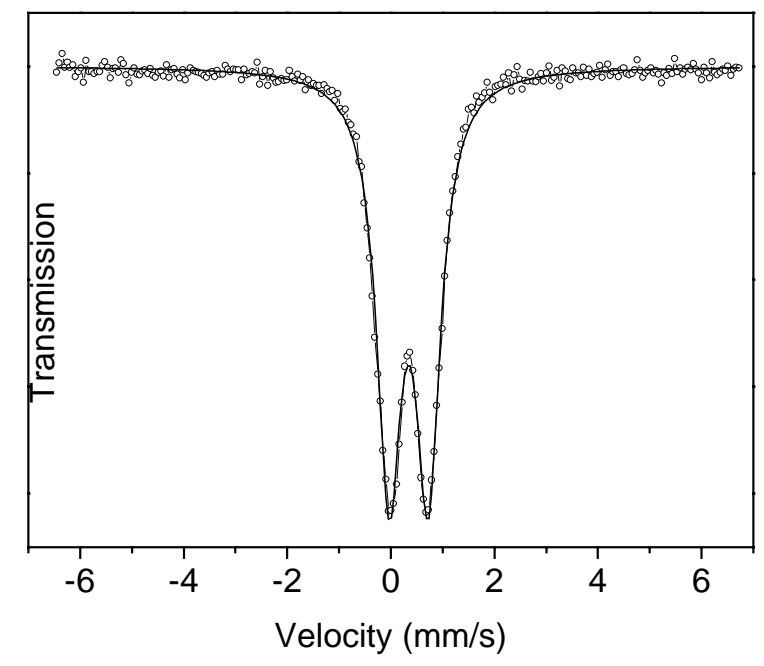

Figure S1. Mössbaur spectrum obtained at $300 \mathrm{~K}$. The full line represents the fit of the spectrum with the low Lorentzian lines. 
A-)

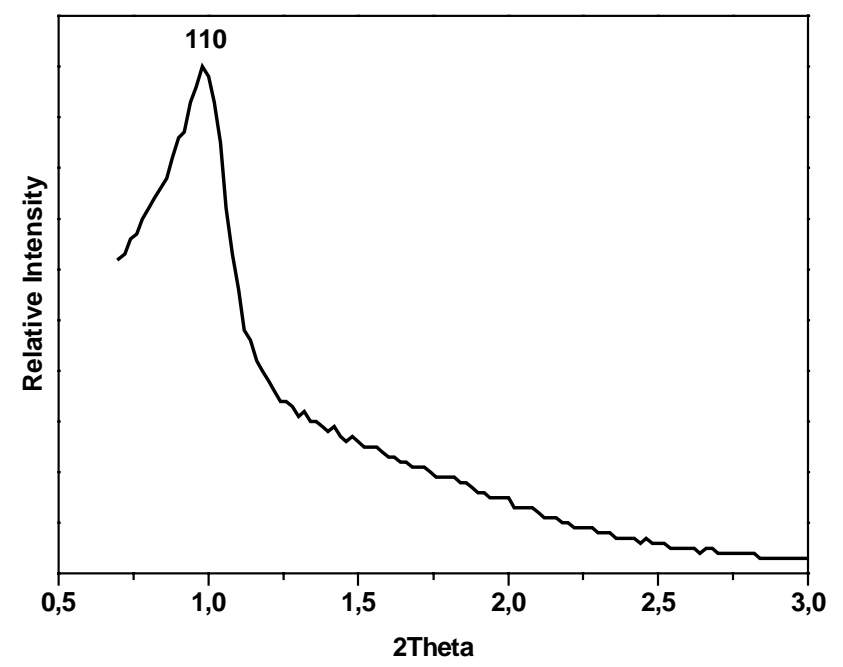

B-)

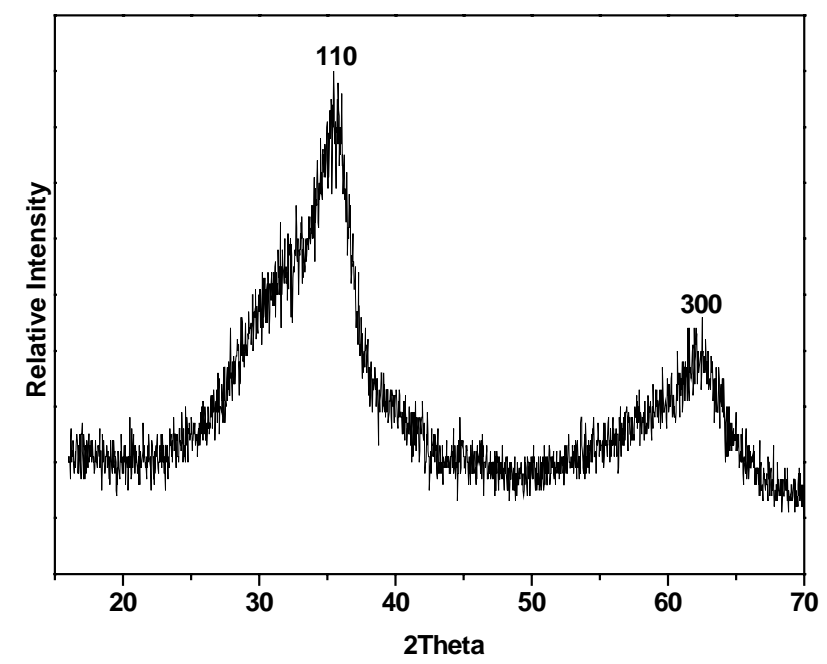

Figure S2 .Low (A) and wide- angle (B) XRD patterns of mesoporous hexagonal ferrihydrite. 


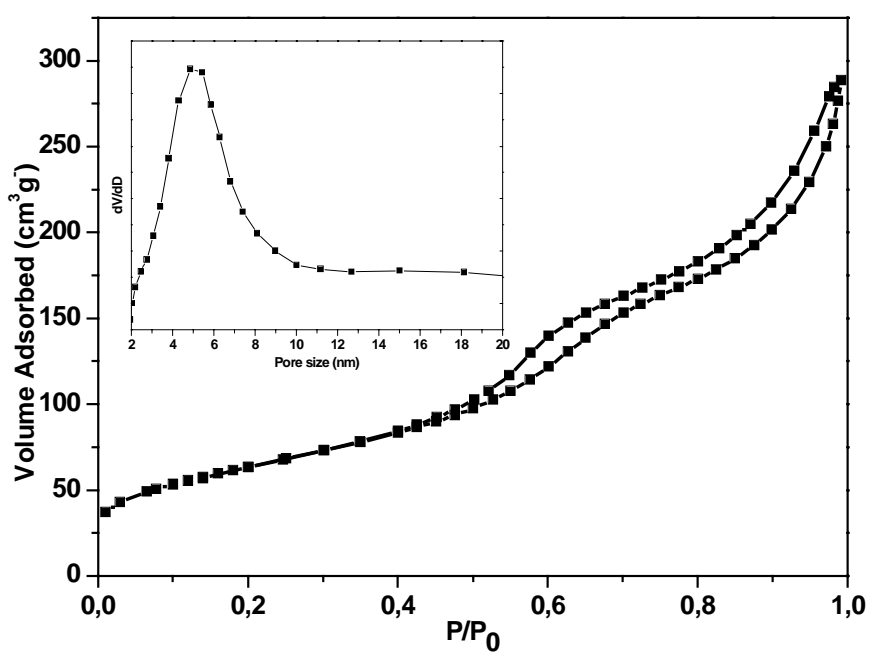

Figure S3. Nitrogen adsorption-desorption isotherms and in insert pore size distribution for hexagonal ordered mesoporous ferrihydrite. 
A-)

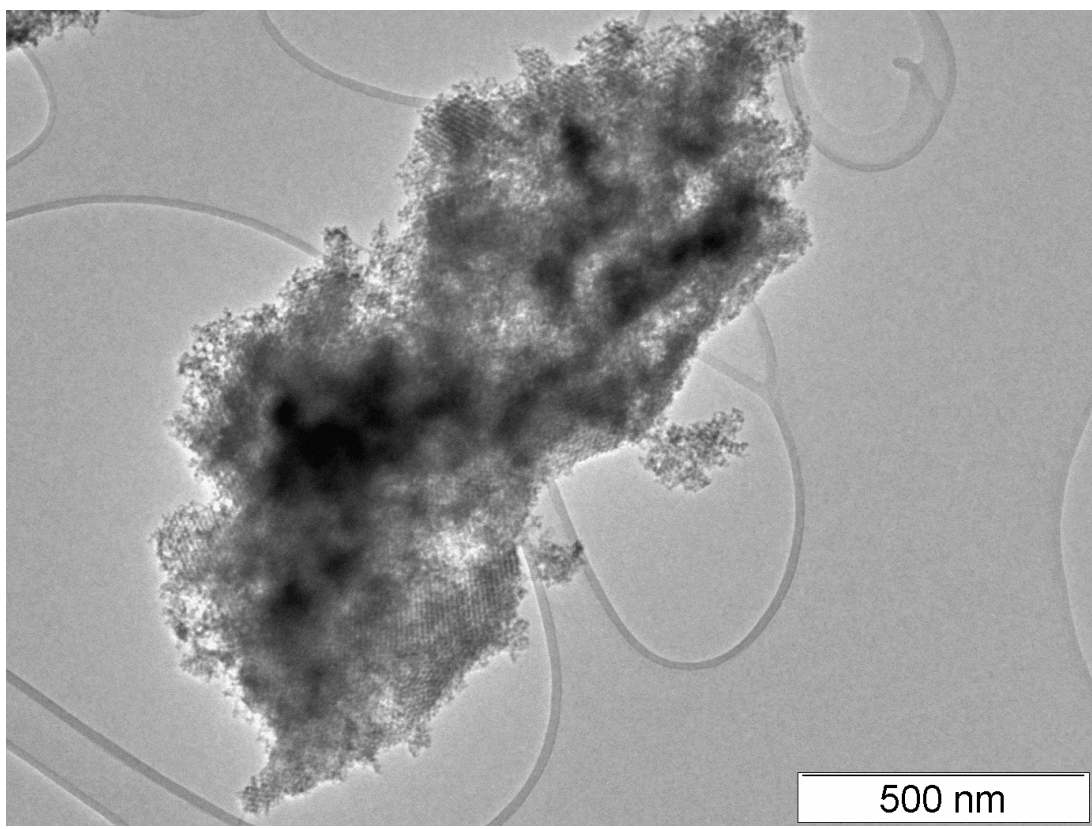

B-)

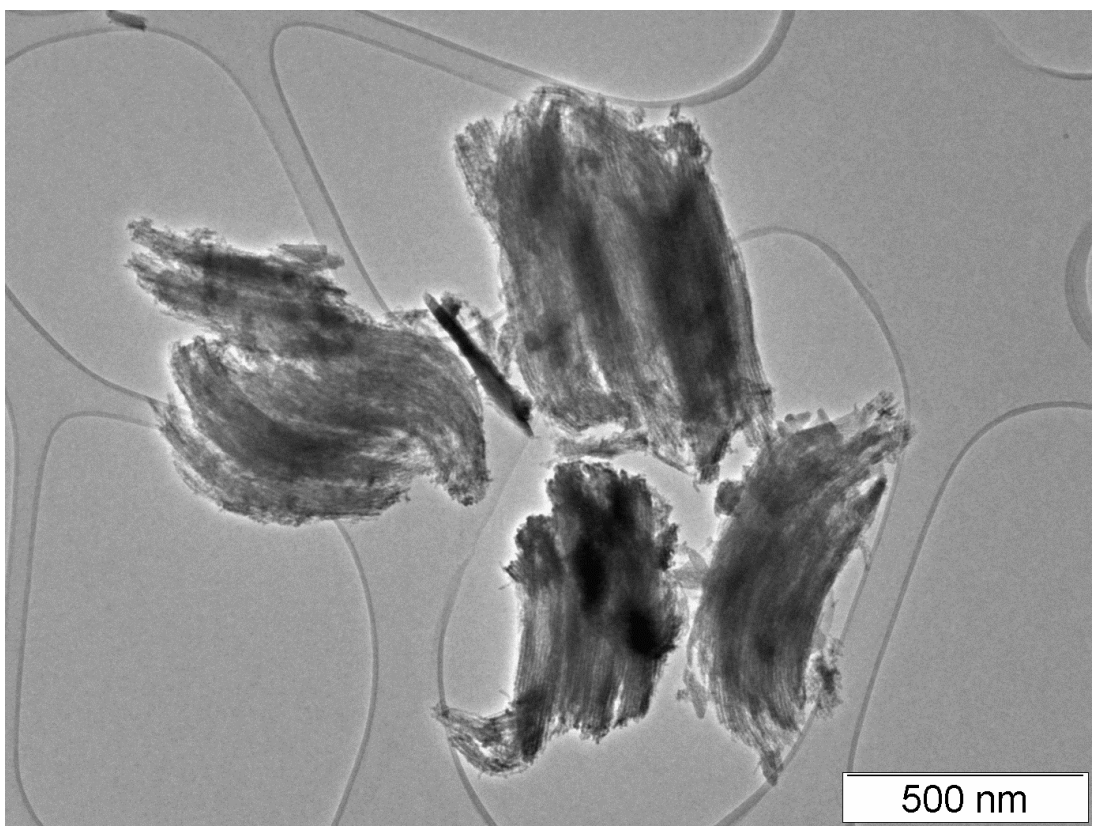

Figure S4: A wider-range TEM pictures of 3D (A) and 2D ferrihydrite (B) 